\title{
MARINE HIGH-SPEED RECIPROCATING INTERNAL COMBUSTION ENGINES INVESTIGATIONS USING ENVELOPE VIBRATION METHOD
}

\author{
Tomasz Lus \\ Polish Naval Academy, Mechanical-Electrical Faculty \\ Śmidowicza Street 69, 81-103 Gdynia, Poland \\ tel.: +4858 6262629, fax: +48586262648 \\ e-mail:t.lus@amw.gdynia.pl
}

\begin{abstract}
The article presents some current diagnostic methods for high-speed marine internal combustion engines in operation. A new exploitation strategy of marine diesel engines (Condition Based Maintenance strategy) requires having a substantial amount of information about the condition of the engines and the most important machinery and systems in conjunction with them.

In the case of high-speed diesel engines, which usually are not factory-fitted with indicating valves, to assess the combustion process, to assess the technical condition and tightness of cylinders and tuning of fuel and valve gear systems can be used other methods such as vibro-acoustic. Test methods of technical condition assessment of the main propulsion engines and auxiliary engines on the basis of low- and high-frequency changing engine operating parameters and on the vibration processes accompanying such processes have been discussed in the paper. Vibration methods are of particular importance when engines are not equipped with cylinder pressure valves. The possibilities offered by the diagnostic method based on the angular selection of the vibrations accelerations envelope in the diagnosis of high-speed marine engines are also presented.
\end{abstract}

Keywords: marine engines, diagnostics, fuel system, valve gear system, vibration method

\section{Introduction}

Competition in today's shipping market forces companies into a systematic exchange transport fleet units. When purchasing new units every company takes into account the costs associated with the operation of the vessel including the costs of main propulsion engines and auxiliary engines $[6,11]$. The most frequent to drive ships of all types and sizes internal combustion piston engines of two- and four-stroke are selected. The vast majority of marine engines are turbocharged to increase their effective power $[10,17]$. In some types of applications not turbocharged engines are still used, for example, when a substantial factor of their operation is reliability and durability. With the development in manufacturing methods of engines and increase the number of commercial fleet the rules of their operation are changing. Older types of engines are still operated under the so-called prevention plan (Preventive Maintenance System - PM). New types of engines are increasingly being exploited by the technical condition (Condition Based Maintenance System -CBM), though in some cases, you cannot go entirely to the new method of reviewing - especially where the rules are dictated by classification societies. The new strategy based on the CBM exploitation, however, requires having a substantial amount of information about the condition of the engines and the most important devices in conjunction with them $[2,5,12,14]$. Gradual transition to the CBM operational strategy is continuous improvement and the development of diagnostic systems of marine internal combustion engines. This article presents an overview of selected methods for diagnosis of marine engines used in the operation. It focuses particularly on the method, which based on the angular selection of vibration signal emitted by the engine running components, which may be useful for diagnosis of high-speed engines, which are not fitted with cylinder pressure valves. 


\section{Methods of marine diesel engines diagnosing in service}

Diagnostic methods used in the exploitation of marine engines can be divided into two main groups: the so-called method based on an assessment of performance parameters of the engines and other methods based on the use of parameters of phenomena, which goes with engine operation [7]. Parametric methods such as method of limiting values of diagnostic parameters and method of trends analysis include analysis so called low-frequency changing process parameters and high-frequency changing process parameters characteristic for piston engines operation. This low-frequency changing process parameters are such as temperature and pressure of cooling water, temperature and exhaust gas pressure, temperature and pressure of the lubricating oil. This highfrequency changing process parameters are such as pressure inside the cylinder, the pressure in the pipes and components of fuel system at the time of injection.

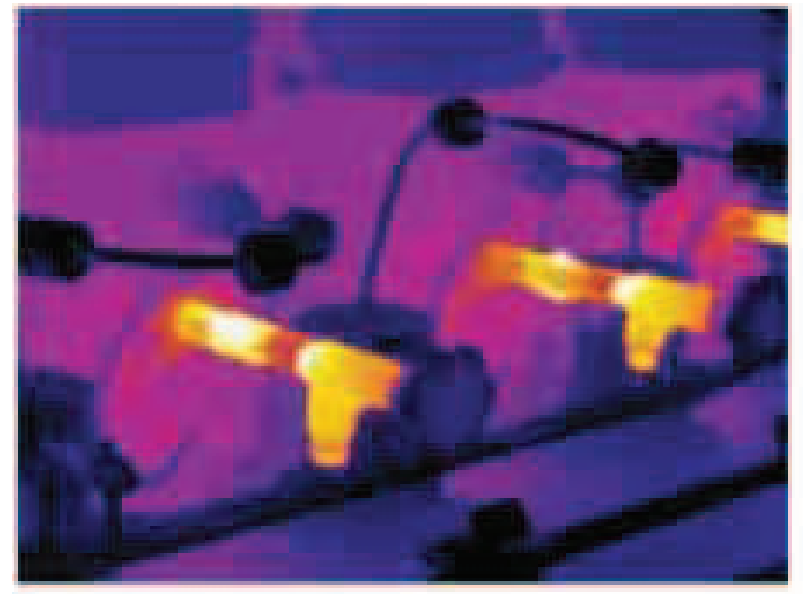

Fig. 1. Example of the use the thermal imaging camera to determine the temperature distribution on the marine engine external surfaces

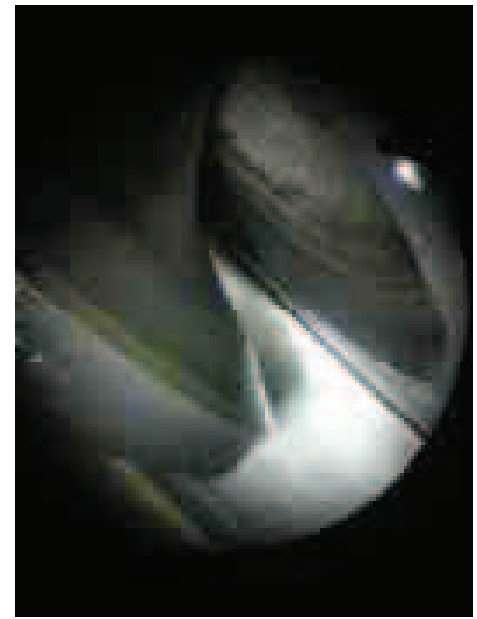

Fig. 2. Examples of the use of an endoscopy to assess the state of the surface of the marine engine valves

Among other diagnostic methods used for reciprocating engines, may be include measurements of the physicochemical properties of lubricating oil, measurements of vibration parameters and the accompanying engine noise [16], the analysis of thermal field emitted by the engine (Fig. 1) or endoscopic inspection of parts and engine components (Fig. 2) which are not accessible from outside. Observing the colour of exhaust gases has been a proven method of preliminary assessment of technical condition of marine diesel engines for long time [4]. Nowadays to assess the combustion process and the technical condition of the engine smoke test station and exhaust gas analyzers are more and more frequent used.

\subsection{Engine diagnosing based on the low-frequency changing process parameters}

Manufacturers of marine diesel engines for years with the technical documentation provide test results that contain stored, usually in tabular form, all the most important engine parameters. These are arranged in an incremental way from $25,50,75,100$ to $110 \%$ of rated output pressures, flow rates, temperatures of gas, oil and water, speeds and other parameters significant for the work of internal combustion engines. In the tabular summaries or graphs boost pressure, the measured value of fuel and cylinder oil consumptions, and the calculated values of parameters such as output power and specific fuel consumption are given. The machinery crew, in the activities performed during the watch, has a duty to record and save in the machine log selected, the most important engine parameters and comparing their values with the guide values contained in the protocol from the trials. 


\subsection{Tests of the lubricating oil parameters - predecessor of piston engines diagnostics}

Systematic research and evaluation of the quality of lubricating oil of piston engines based on physico-chemical analysis of selected indicators is considered to be the beginning of the modern diagnosis of marine engines. Research of viscosity ratios, ignition temperature, the number of alkaline, water content and solids content at regular intervals is necessary for safe and economical maintenance of the engine lubricating oil for a long time by its state. Before the introduction of this method, the owners were forced to perform an oil exchange at regular intervals - e.g. every year, every two years, as recommended by engine manufacturers - which greatly increased the operating costs of vessels. Today machine crew carried out the trend analysis of basic properties of the lubricating oil exchanging the oil considerably less, and only when one of the indicators being monitored exceeds the limit. Oil tests are done in laboratories on land or on a ship on the basis of diagnostic kits usually delivered by suppliers of oils and fuels.

\subsection{Engine diagnosing based on the high-frequency changing process parameters}

The high-frequency changing process parameters used in the methods of engine diagnosis are usually internal cylinder pressure, sometimes the pressure in selected parts of fuel injection systems. Measurement and recording of the pressure curves in the cylinders are made for the engines, which are equipped with cylinder pressure valves. Pressure curve in the cylinder can best evaluate the combustion process - the process that is the most relevant for the assessment of the efficiency of engine operation $[13,15,18]$. The most common practice in measurement of internal cylinder pressure is used temporarily mounted sensors on the indicator valves. Sometimes the pressure sensors are installed permanently on duplicate indicator valve, but the time of their work is limited to several minutes or periodic measurements - remaining time the pressure sensors on the indicator valves are cut off from the exhaust gases stream by barrier valves. This measurement technique is a result of the relatively small resistance of pressure sensors for long-term exposure to high temperature of exhaust gases. In specific cases, custom solutions are used to measure the pressure inside the cylinder indirectly. For example, with the sensor mounted on the screw cap ties and sensor mounted just below the surface of the cylinder head from the sidewall of the combustion chamber - but such solutions require relatively frequent calibration of the pressure measuring circuit. There are several companies that provide specialized testers and internal cylinder pressure recorders on the market $[17,20]$. Some of the testers to register internal cylinder pressure course, in addition to the pressure sensor need to connect the crankshaft position sensor (Fig. 3).
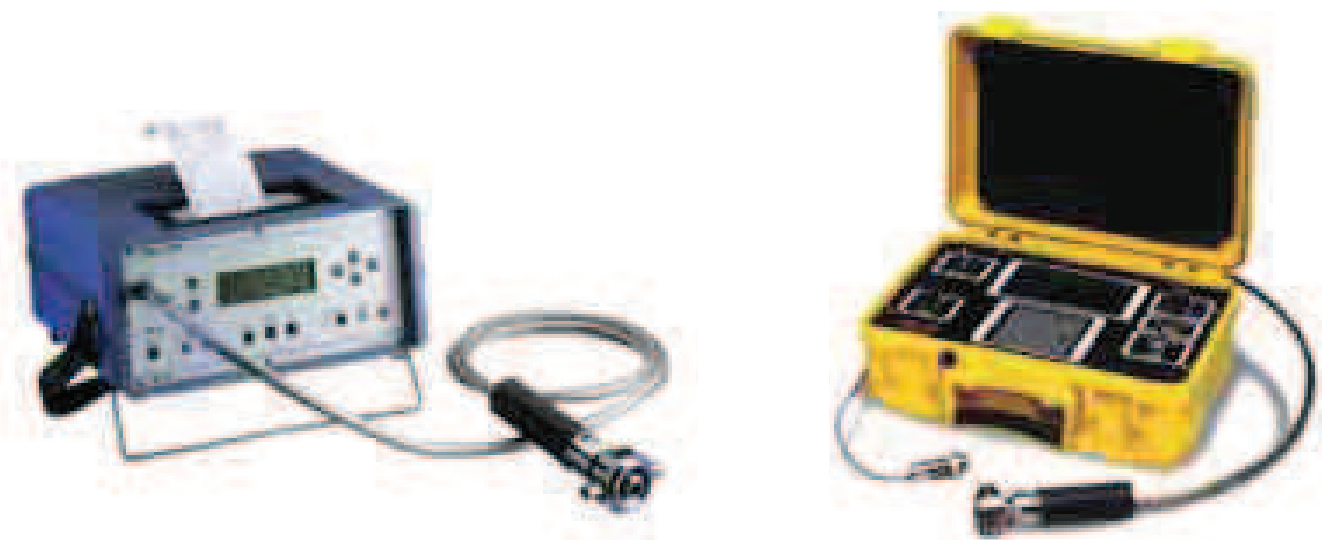

Fig. 3 Marine engines testers and indicating pressure recorders without and with crankshaft angular position sensor [20]

In marine diesel engines that have more than one fuel injection valve per cylinder, it is possible to measure the fuel pressure in the course of time between the high pressure injection pump and 
injectors. The measurement system is operating on an element separating the fuel stream from the pump flows to the individual injectors. On the smaller engines, where each cylinder has only one fuel injector, the measurement of fuel injection pressure is usually impossible because of the fire safety provisions prohibiting any interference with the high pressure fuel system. Differences in indicating pressure waveforms and injection pressure waveforms between cylinder systems and exceptions to the registered fuel injection pressure on the course of a standard service engine allow drawing conclusions about the combustion process, the technical condition of the cylinder and the state of fuel injection pumps and injectors tuning. Example, characteristic for slow-speed twostroke marine diesel engine indicated pressure curve inside the cylinder, the fuel pressure in the injection pipe and vibrations envelope accompanying the work of the injector, registered on engine analyzer constructed at the Polish Naval Academy in Gdynia, is shown in Fig. 4.

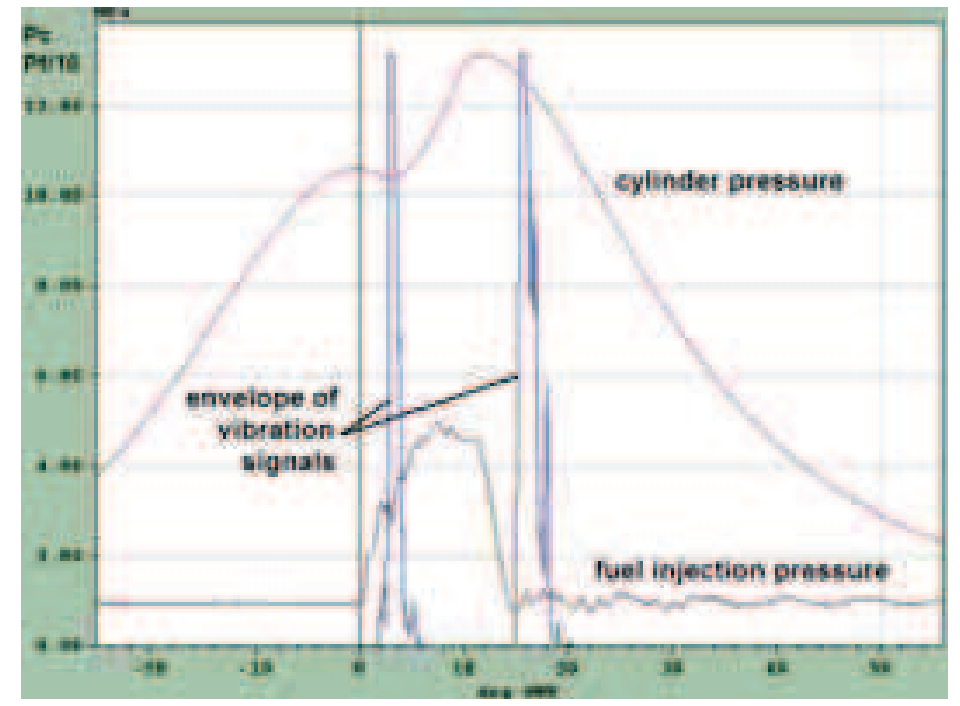

Fig. 4. Indicated cylinder pressure curve, the fuel pressure in the injection pipe and the envelope of acceleration vibration recorded at the injection valve [8]

The analyzer automatically or operator of the analyzer, using a cursor, could read out the values of angles and pressures which associated characteristic points of high frequency changing parameters occurring in the cylinders and other parts and systems of running engine. On the highspeed engines, which are generally not equipped with indicating valves, cylinder pressure relief valves could be used for this purpose. Measurements in this case, however, require some interference in the design structure of the engine and affect its reliability during start-up. The next chapter will present a method, which allows avoiding the limitations in the diagnosis of high-speed diesel engines through the use of vibration methods.

\section{High-speed diesel engine diagnosing based on vibration parameters}

In the case of high-speed diesel engines, which usually are not factory-fitted with indicating valves, to assess the combustion process, to assess the technical condition and tightness of cylinders and tuning of fuel and valve gear systems can be used other methods such as vibroacoustic. Typical methods for the vibration signal analysis in time or frequency domain usually offer a limited amount of information $[1,3,9]$. Presented in the paper method is the visual analysis in the crank angle domain of the vibrations signal envelope generated by the functional systems of the running engine. This method was developed at the Polish Naval Academy for the slow-, and medium-speed engines and is still developed for other types of marine high-speed diesel engines.

Vibration signal in this method is analyzed as an event on the time / crank angle axis. At sufficiently high sampling rate and a stable time / angle axis, with appropriate reference signal to 
determine the characteristic points / events of the running engine in the course of vibration can be relatively easy (Fig. 5 and 6). The proper order of occurrence of specific vibration signals (correct and repetitive nature of the vibration waveform) means that the engine is in good condition. In the case of multi-cylinder engine, when you need to simultaneously analyze multiple overlapping vibration signals from various sources, there may be problems with the interpretation of test results.

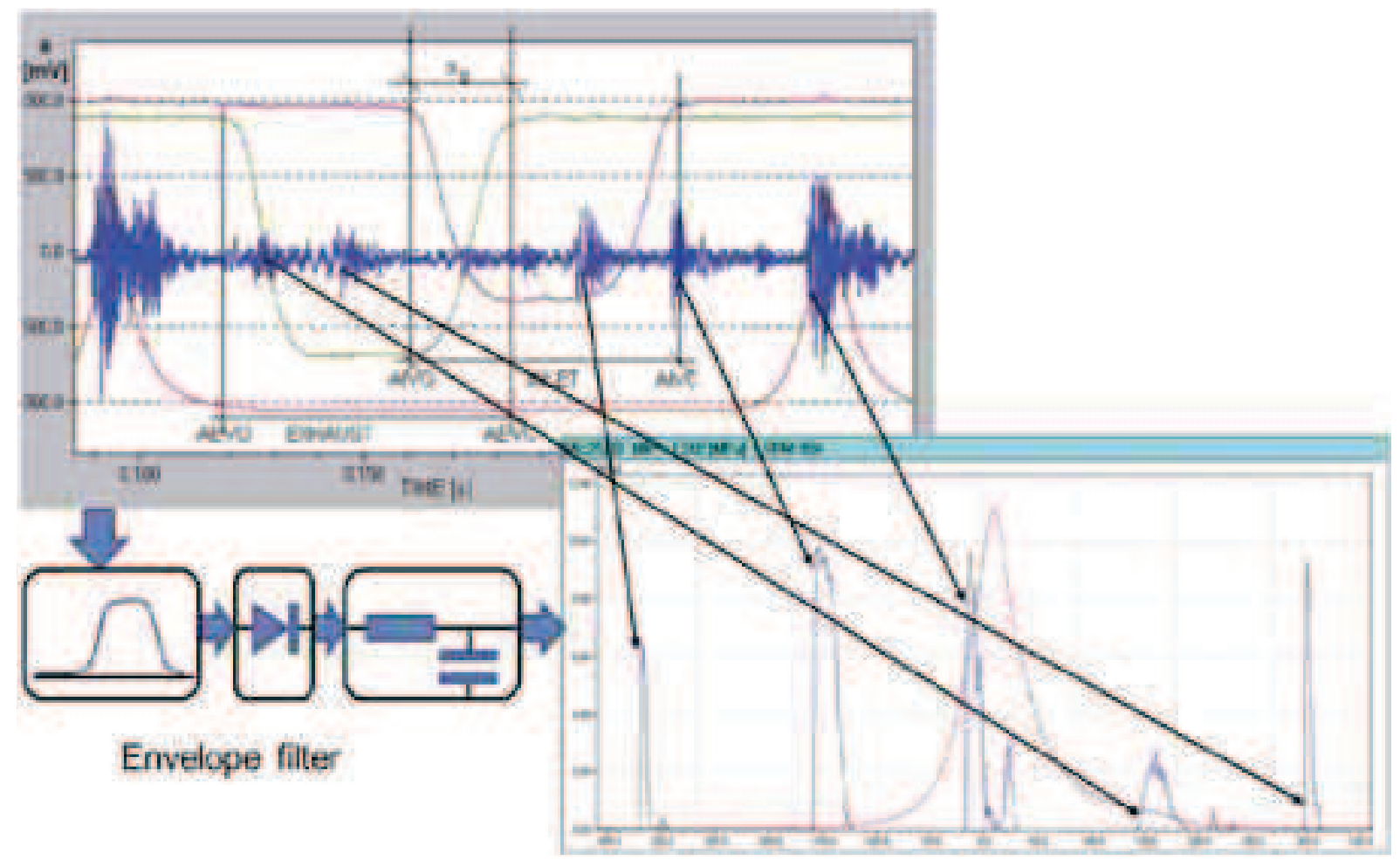

Fig. 5. Schematic illustrating how the transposition of the vibration signals in the time domine corresponding to the angular engine cycle, $\alpha p$ - the dynamic angle of valves overlap, AEVO - the dynamic angle of the exhaust valve opening, AEVC - the dynamic angle of the exhaust valves closing, AIVO - the dynamic angle of the intake valve opening, AIVC - the dynamic angle of the intake valve closing

Using the vibration acceleration envelope waveform analyzer equipped with a the "zoom" function (which is presented in Fig. 6), operator can zoom in each part of the vibration curve and use the cursor to read-out the dynamic parameters such as characteristic engine timing points.
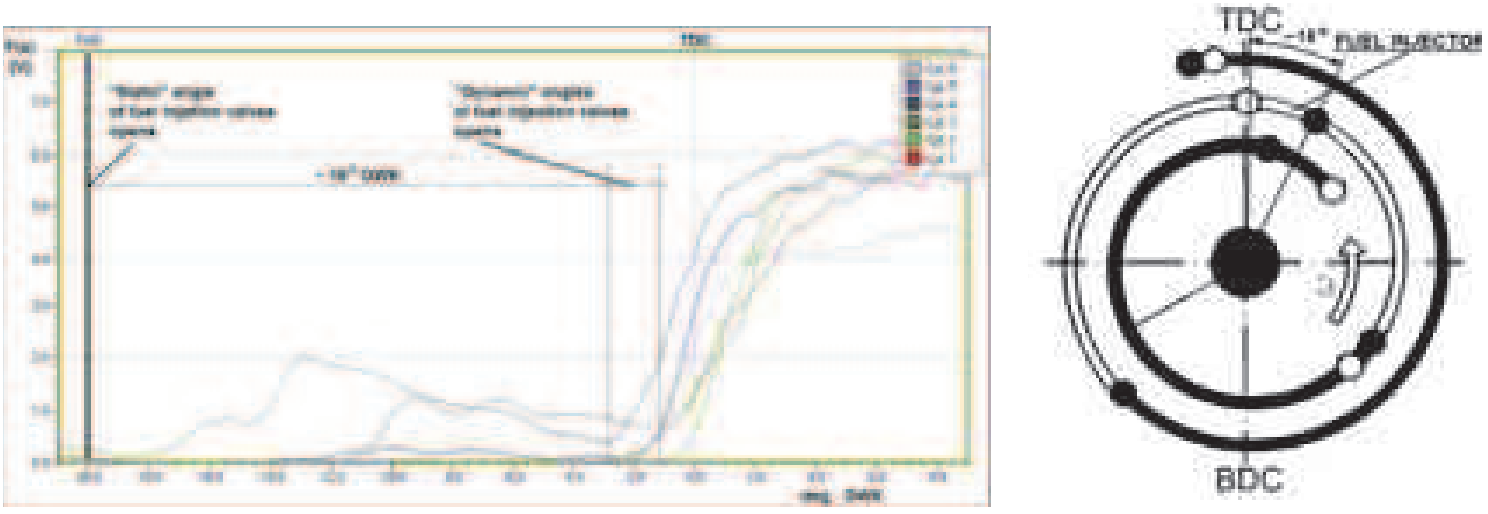

Fig. 6 Dynamic and static angle values of start of fuel injection in high-speed diesel engine[21]

Differences between dynamic and static values of angle parameters are very good seen on the fuel injection angle value. In this particular case they are connected also with fuel injection angle mechanic-hydraulic actuator, which exists on the engine. 
Using the cursor operator of the analyzer can determine the beginning of the opening angles of the fuel injectors, opening and closing intake and exhaust valves of a cylinder in the engine with enough to adjust (or check the status of regulation) accuracy (Fig. 7 and 8).

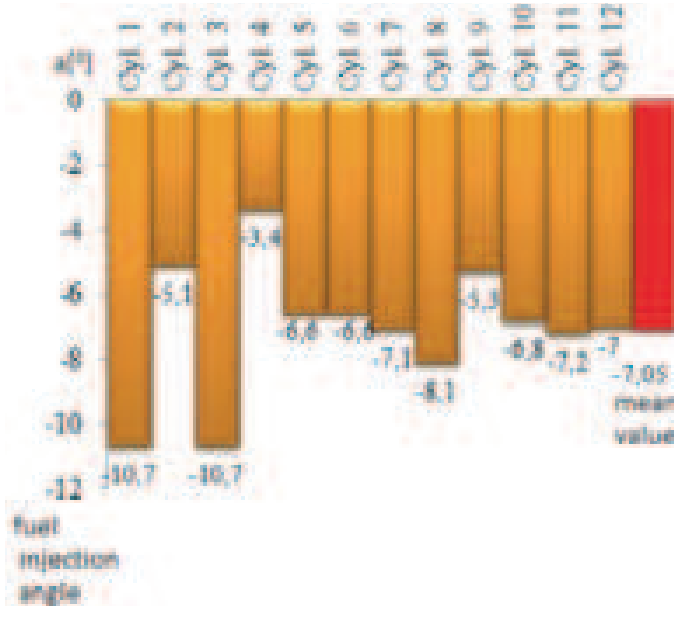

Fig. 7. Values of starts of fuel injection angles of 12 cylinder high-speed marine diesel engine

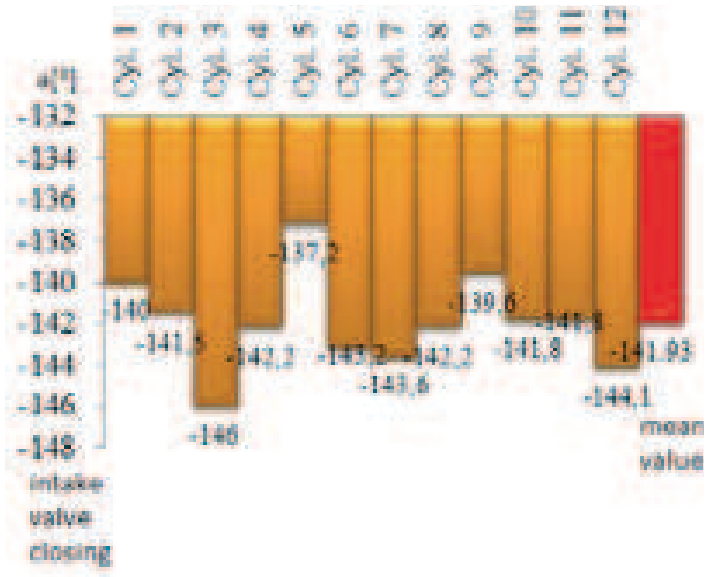

Fig. 8. Values of intake valve closing angles of 12cylinder high-speed marine diesel engine

This method gives good results especially on multi-cylinder units with speed range up to 2000 rpm. The advantage of the method is in simultaneous collecting vibration signals from several points on the running engine block. The disadvantage of the method exists in the necessity of mounting several sensors on cylinder heads or block connecting bolts. Sensors are fitted to the engine by glue or by screw holders.

Now a day's method is tested and evaluated on many types of high-speed marine and notmarine diesel engines of different size - from one- to twelve- and more cylinders.

\section{Conclusions}

1. Assessment of technical condition of marine internal combustion diesel engines in operation, is a very complex process. So for this purpose all available methods, which are effective and not too expensive, are used.

2. Most of the malfunctions in marine engines are generated by the fuel system and valve gear mechanism. Following the instructions crew operating machinery is required for relatively frequent inspections the technical condition of these (and other) engine systems.

3. Opening and closing of a fuel injection valves, opening and closing the intake and exhaust valves on the engine are the sources of vibration signals. The propagation of these signals occurs in the entire structure of the engine. There are several tools to analyze the changes in the nature of the vibration signal waveform, which are used in condition monitoring systems of the equipment in real time.

4. The presented method of vibration signal processing makes it possible to determine the socalled "dynamic" timing for the engine. The recorded "dynamic" timing angles are different from "static" timing angles taken from engine manuals. The angles of engines dynamic timing are affected by rotational speed, engine load, the operation of automatic injection advance angle change mechanism and changes the angles of opening and closing valves. Taking into account the fact that the engine tests may be conducted at different load conditions, one must have registered dynamic parameters for a wide range of engine loads.

5. Despite some limitations resulting from the very essence of the method and design of marine internal combustion engines presented method can be useful for marine and not-marine highspeed engines diagnosing, especially when they are not fitted with indicating valves. 


\section{References}

[1] Batko, W., Dąbrowski, Z., Nowoczesne metody badania procesów wibroakustycznych, Wydawnictwo i Zakład Poligrafii Instytutu Technologii Eksploatacji, PIB, Radom 2006.

[2] Bengtsson, M., Condition Based Maintenance System Technology - Where is Development Heading?, Euromaintenance 2004, Proceedings of the $17^{\text {th }}$ European Maintenance Congress, AMS (Spanish Maintenance Society), Barcelona, Spain 2004.

[3] Brüel \& Kjǽr, Machine Diagnostics Toolbox Industrial Solutions, 2006.

[4] Hupli, J., Troberg, M., The smokeless Sulzer ZA40S, Wärtsilä Marine News No. 1, 2005.

[5] Kennedy, R., Examining the Processes of RCM and TPM, The Plant Maintenance Resource Center, The Centre for TPM, Australasia, 2005.

[6] Klockars, T., Eykerman, A., Mayr, I., Making the most of perfect maintenance timing, indetail, Wärtsilä Technical Journal, pp. 57-60, Finland 2010.

[7] Kluj, S., Diagnostyka Urządzeń Okrętowych, SDK WSM, Gdynia 2000.

[8] Lus, T., Envelope vibration method in diesel engine dynamic tuning, EXPLO-DIESEL \& Gas Turbine'01, Gdańsk-Międzyzdroje-Copenhagen 2001.

[9] Madej, H., Diagnozowanie uszkodzeń mechanicznych w silnikach spalinowych maskowanych przez elektroniczne urzadzenia sterujace, Wydawnictwo Naukowe Instytutu Technologii Eksploatacji - PIB, Radom 2009.

[10] MAN Diesel, First All-Electronic Four-stroke engine, DIESEL FACTS, No. 3, Copenhagen 2006.

[11] MAN B\&W Marine Engine Programmme $3^{\text {rd }}$ edition and other information leaflets, 2006.

[12] Moubray, J., Reliability-Centered Maintenance, TWI Press, Inc. Terre Haute, IN 47807, 2000.

[13] Polanowski, S., Errors of piston TDC reference to zero points of cylinder pressure derivatives of marine engines, $27^{\text {th }}$ International Scientific Conference on Combustion Engines KONES2000, Nałęczów, Poland 2000.

[14] Sondalini, M., Condition Based Maintenance Strategy (C) Copyright lifetime-reliability.com 2004.

[15] UNITEST Marine \& Industrial Diesel Engine Tester UNITEST-203.

[16] Visser, K., Diesel engine diagnostics at work, SWZ, 1991.

[17] Wärtsilä Total Service Product Programme and other information 2006.

[18] Wimmer, A., Glaser, J., Indykowanie silnika, Wydawnictwa Instytutu Zastosowań Techniki, Warszawa 2004.

[19] Operation Manual for DOOSAN - MAN B\&W Diesel Engines 7S60MC-C.

[20] Materiały reklamowe firm KISTLER, Dive Time i inne.

[21] Lus, T., Tunnig method for high-speed marine Diesel engine MB820 type, Journal of KONES Powertrain and Transport, Vol. 17, No. 2, pp. 277-284, Warszawa 2010. 